\title{
Evaluation of Different Inoculation Methods for Mango Anthracnose Disease Development
}

\author{
Pavitra Kumari*, Rajender Singh and Rakesh Punia \\ Department of Plant Pathology, CCS Haryana Agricultural University, \\ Hisar-125 004, Haryana, India \\ *Corresponding author
}

\section{A B S T R A C T}

Keywords

Inoculation methods, Mango anthracnose disease.

Article Info

Accepted:

24 September 2017

Available Online:

10 November 2017
The aim of this study was to evaluate different inoculation methods for disease development in mango. For this rationale the present investigation was carried out under laboratory conditions during, 2016 at CCS, HAU, Hisar. The variation in different inoculation method for mango anthracnose development was tested by spray, pinprick and dipping inoculation method. All these three different method of inoculation established its pathogenic nature producing anthracnose symptoms on the inoculated green leaves and fruits. The disease symptoms appeared on mango leaves and fruits after 36 hours of pin prick inoculation method at $25 \pm 1^{\circ} \mathrm{C}$. However, disease symptoms appeared on leaves and fruits after 48 hours of spray and dipping inoculation methods at $25 \pm 1^{\circ} \mathrm{C}$. Maximum disease severity of 71.1 and 77.7 per cent was recorded on mango leaves and fruits, respectively, when leaves and fruits were inoculated by pin prick method.

\section{Introduction}

Anthracnose of mango (Mangifera indica L.), is one of the devastating pre and post-harvest fungal disease which has wide occurrence and causing substantial yield losses. In India, few decades ago, the anthracnose of mango was considered a disease of minor importance but recently this disease is a serious handicap in successful cultivation of mango. Colletotrichum gloeosporioides (Penz. and Sacc.), the causal fungus of mango anthracnose disease is a ubiquitous pathogen. The fungus has wide host range and infects about 470 different host genera (Prusky and Plumbley, 1992). It causes diseases in many annual, biennial and perennial plants. This pathogen causes infection on foliage, stems and fruits. C. gloeosporioides follows the hemi-biotrophic mode of infection where, biotrophic and necrotrophic phases are consecutively occur (Munch et al., 2008). In literature, different inoculation methods are available for proving the pathogenic nature of the C. gloeosporioides on many crops. Hasabins (1984) and Rathod (1994) proved that $C$. gloeosporioides was pathogenic on mango fruits. The fungus produced typical anthracnose lesions within 72 hours in unwounded and within 48 hours in wounded fruits. Patel (2000) also reported that tooth brush injury method found more efficient in development of anthracnose symptoms followed by pinprick method. Jagadish et al., 
(1992) reported the development of symptoms only on wounded fruit on inoculation and the disease severity was highest on ripe fruit. The pathogenicity of the fungus $C$. gloeosporioides was also proved by Reddy (2000) using pin prick method on citrus, ber and strawberry. Keeping in view, the mode of infection of $C$. gloeosporioides there is need to test different inoculation methods on mango leaves and fruits for proving pathogenic nature of this fungus. Therefore, the present study was carried out with the objective to evaluate the efficacy of different inoculation methods viz. dipping, spray and pin prick under laboratory conditions for proving the pathogenic ability of the fungus C. gloeosporioides.

\section{Materials and Methods}

\section{Evaluation of different inoculation methods for disease development}

The variation in different inoculation method for mango anthracnose (C. gloeosporioides) development was tested by spray, pinprick and dipping inoculation method.

\section{Spray inoculation method}

For this purpose healthy mango leaves and fruits were collected from experimental orchard of Department of Horticulture, CCS HAU, Hisar. Both the leaves and fruits were washed in tap water, followed by surface sterilization with alcohol and then rinsed three times in sterile distilled water and blot dry under laboratory conditions. The spore suspension was made from ten days old culture of $C$. gloeosporioides in sterile distilled water. The leaves and mango fruits were inoculated by spraying spore suspension $\left(10^{6}\right.$ spores $\left./ \mathrm{ml}\right)$ separately. A hand atomizer was used for spraying the suspension and atomizer was pre sterilized with 90 per cent ethanol before the spraying. The inoculated leaves and fruits were kept in desiccators for incubation at $25 \pm 1^{\circ} \mathrm{C}$ temperature and $\geq 90$ per cent relative humidity in BOD incubator, separately. The desiccators containing five leaves/ two fruits were arranged in a complete randomize design with three replications. Observations were recorded for first appearance of anthracnose symptoms. The disease severity was calculated at 10 days after inoculation by adopting 0-5 disease rating scale (McKinney, 1923) as detailed below:

Per cent disease severity was calculated by using following formula given by (Prabakar et al., 2005).

Sum of individual ratings Per cent disease severity $=-\times 100$ Total no of leaves observed $x$ maximum grade

\section{Pinprick method}

The surface sterilized mango leaves and fruits were inoculated using the wound which included pinprick the fruits as well as leaves with a sterile needle by dipping in spore suspension, $10^{6}$ spores/ml (Patel, 1978). The inoculated leaves and fruits were kept in desiccators for incubation at $25 \pm 1^{\circ} \mathrm{C}$ in BOD incubator, separately. The desiccators containing five leaves/ two fruits were arranged in a CRD with three replications. Observations were recorded for first appearance of anthracnose symptoms. The disease severity was calculated at 10 days after inoculation by using formula given by (Prabakar et al., 2005).

\section{Dipping method}

The surface sterilized mango leaves and fruits were inoculated by dipping the fruits as well as leaves in the spore-suspension $\left(10^{6}\right.$ spores $\left./ \mathrm{ml}\right)$ of $C$. gloeosporioides (Hasabnis, 1984). The inoculated leaves and 
fruits were kept in desiccators for incubation at $25 \pm 1^{\circ} \mathrm{C}$ in BOD incubator, separately. The desiccators containing five leaves/ two fruits were arranged in a complete randomize design with three replications. Observations were recorded for first appearance of anthracnose symptoms. The disease severity was calculated at 10 days after inoculation by using formula given by (Prabakar et al., 2005). The data from the experiments were analysed by using relevant statistical software (OPSTAT http://hau.ernet.in).

\section{Results and Discussion}

\section{Evaluation of different inoculation methods for disease development}

The efficacy of different inoculation methods viz. dipping, spray and pin prick was tested under in vitro conditions for proving the pathogenic ability of $C$. gloeosporioides. The results are presented in Table 1.

It is clearly indicated from the data presented in Table 1 that $C$. gloeosporioides was capable of infecting leaves and fruit of mango. C. gloeosporioides invaded the host tissues through the injured as well as intact surface of leaves and fruits showing clearly their pathogenic ability. All the three different method of inoculation viz. dipping, spray and pin prick method established its pathogenic nature producing anthracnose symptoms on the inoculated green leaves and fruits. The disease symptoms appeared on mango leaves and fruits after 36 hours of pin prick inoculation method at $25 \pm 1{ }^{\circ} \mathrm{C}$. However, disease symptoms appeared on leaves and fruits after 48 hours of spray and dipping inoculation methods at $25 \pm 1{ }^{\circ} \mathrm{C}$. Maximum disease severity of 71.1 and 77.7 per cent was recorded on mango leaves and fruits, respectively, when leaves and fruits were inoculated by pin prick method. Lowest disease severity of 20.0 and 27.7 per cent was observed on leaves and fruits, respectively, when leaves and fruits were inoculated by spray method. However, dipping of leaves and fruits in C. gloeosporioides spore solution expressed disease severity of 55.5 and 61.1 per cent on leaves and fruits, respectively. In India, scanty information has been available in literature regarding the evaluation of different inoculation methods for disease development under laboratory conditions.

Thus result obtained during the investigation was in accordance with Patel, (1978; 2000) and Parashar (2013), where they reported that pin prick method was most superior over other inoculation methods on mango and chilli leaves as well as fruits, respectively. The disease symptoms appeared within 36 to 48 hours on pin prick inoculated leaves and fruits, while symptoms appeared within 72 hours on unwounded leave (Hasabnis, 1984; Rathod, 1994; Patel, 2000).

The disease severity was calculated at 10 days after inoculation by adopting 0-5 disease rating scale

\begin{tabular}{|l|c|}
\hline Grade & Leaf/fruit area affected \\
\hline 0 & No infection \\
\hline 1 & Up to 5 per cent \\
\hline 2 & $6-10$ per cent \\
\hline 3 & $11-20$ per cent \\
\hline 4 & $21-50$ per cent \\
\hline 5 & $>50$ per cent \\
\hline
\end{tabular}


Table.1 Effect of different inoculation methods on disease development of mango fruits and leaves

\begin{tabular}{|c|c|c|c|}
\hline $\begin{array}{c}\text { Inoculation } \\
\text { methods }\end{array}$ & $\begin{array}{c}\text { Appearance of symptoms } \\
\text { on leaves and fruit }\end{array}$ & $\begin{array}{c}\text { Per cent disease } \\
\text { severity on leaves* }\end{array}$ & $\begin{array}{c}\text { Per cent disease } \\
\text { severity on fruits* }\end{array}$ \\
\hline Spray & After $48 \mathrm{~h}$ & $20.0(26.3)$ & $27.7(31.5)$ \\
\hline Dipping & After $48 \mathrm{~h}$ & $55.5(48.1)$ & $61.1(51.4)$ \\
\hline Pinprick & After $36 \mathrm{~h}$ & $71.1(57.4)$ & $77.7(62.1)$ \\
\hline \multicolumn{2}{|c|}{ C.D. $(\mathrm{p}=0.05)$} & $(8.4)$ & $(1.1)$ \\
\hline C.V. & 8.2 & 0.9 \\
\hline
\end{tabular}

* Mean of five replications

The efficacy of different inoculation methods viz. dipping, spray and pin prick were tested under in vitro conditions for proving the pathogenic ability of the fungus $C$. gloeosporioides. The fungus $C$. gloeosporioides was capable of infecting leaves and fruit of mango. C. gloeosporioides invaded the host tissues through the injured as well as intact surface of leaves and fruits showing clearly their pathogenic ability. All the three methods of inoculation viz. dipping, spray and pin prick method established its pathogenic nature producing anthracnose symptoms on the inoculated green leaves and fruits. The disease symptoms appeared on mango leaves and fruits after 36 hours of pin prick inoculation method at $25 \pm 1^{\circ} \mathrm{C}$.

\section{References}

Hasabins, S. N. (1984). Studies of storage rot of mango (Mangifera indica L.) fruits caused by Colletotrichum gloeosporioides Penz. and Botryodiplodia theobromae Pat. M.Sc. Thesis, Konkan Krishi Vidhyapeeth, Dapoli, India.

http://hau.ernet.in (OPSTAT). CCS HAU, Hisar, Haryana.

Jagadish, C., Pathak, V. N. and Chandra, J. (1992). Incidence, infection process and management of anthracnose of mango fruits. J. Mycol. Pl. Pathol., 22: 35-38.

McKinney, H. H. (1923). Influence of soil temperature and moisture in inhibition of wheat seedling by Helminthosporium sativum. Journal of Agriculture Research 26: 195-217.

Munch,S., Lingner, U., Floss, D.S., Ludwig, N., Sauer, N. and Deising, H.B. 2008. The hemibiotrophic lifestyle of Colletotrichum species. Journal of Plant Physiology, 2008; 165: 41-51.

Parashar, N. K. (2013). Characterization of Colletotrichum gloeosporioides (Penz. and Sacc.) causing die back and fruit rot of chilli (Capsicum annum L.) under south Gujarat. M. Sc. (Agri.) Thesis. Navsari Agricultural University, Gujarat.

Patel, J. C. (1978). Studies regarding anthracnose of mango caused by Colletotrichum gloeosporioides (Penz. and Sacc.) Colletotrichum gloeosporioides (Penz. and Sacc.). $M$. Sc. (Agri.) Thesis. Gujarat Agricultural University, S. K. Nagar.

Patel, R.V. (2000). Studies on leaf spot (Colletotrichum gloeosporioides Penz. and Sacc.) of turmeric (Cucuma longa L.) under South Gujrat conditions. M.Sc. Thesis, GAU, S.K. Nagar.

Prusky, D. and Plumbley, R.A. (1992). Quiescent infections of Colletotrichum in tropical and subtropical fruits. In: Bailey, J.A. and Jeger, M.J. editors. Colletotrichum: Biology, pathology and control. Wallingford: CAR 
International, pp. 289-307.

Rathod, H. L. (1994). Studies on fruit rot of mango (Mangifera indica L.) caused by Colletotrichum gloeosporioides Penz. M.Sc. Thesis, Mahatma Phule Krishi Vidyapeeth, Rahuri. morphological, cultural and pathogenic variations among the isolates of Colletotrichum gloeosporioides (Penz. and Sacc.) of some subtropical fruits. M.Sc. Thesis, University of Agricultural Sciences, Bangalore, p. 69.

Reddy, B. P. N. (2000). Studies on

\section{How to cite this article:}

Pavitra Kumari, Rajender Singh and Rakesh Punia. 2017. Evaluation of Different Inoculation Methods for Mango Anthracnose Disease Development. Int.J.Curr.Microbiol.App.Sci. 6(11): 3028-3032. doi: https://doi.org/10.20546/ijcmas.2017.611.355 